\title{
Breaking the Code of Gender Barrier to Leverage the Position of Women in Indian Workplaces
}

MitashreeTripathy ${ }^{\dagger}$

\section{Abstract}

Studies on gender diversities have always converged on the predicament of women in every field of life which requires much attention and compassion. There is, in fact, a broad domain of issues which need directions and resolutions in order to battle off the stereotypes and prejudices against woman especially at male-dominated fields. The workplace is one of them. Women at work-places worldwide, as researches detail, face numerous obstacles and barriers most typical being the gender biased barrier that restrict them to climb the ladder of success and height. The context in India is as much the same or worse. Discouragement, stereotyping, inequality are few of the many barriers, women face every day at Indian workplaces. Although the working patterns, sharing time with authorities, allotment of roles, among men and women do not differ still men are promoted. Men at workplaces are not affected by the hardships faced by the women as Indian culture is deeply rooted with a stereotyped mindset towards women. The concept of marriage, maternity and family obligations is assumed to be women's only eminence and hence, considered to be one of the most significant barriers in contributing to organisational success. Neither family nor organisations support women to elevate their position, status and dignity at workplaces. This paper explores the theory of gender and gender discrimination at workplaces in the Indian context. The paper also delves into the types of gender barriers at workplaces in the Indian scenario that puts women into complicated situations. Further, the paper explores the battling techniques to break the gender barrier through competencies and essential skills.

Keywords: Gender Barriers, Inequality, Discrimination, Workplaces, India

\footnotetext{
${ }^{\dagger}$ Assistant Professor, Department of Humanities, Orissa Engineering College, Bhubaneswar, Odisha, Email: mitashreetripathy84@gmail.com

(C) 2018 Tripathy. This is an Open Access article distributed under the terms of the Creative Commons Attribution License (http://creativecommons.org/licenses/by/2.0), which permits unrestricted use, distribution, and reproduction in any medium, provided the original work is properly cited.
} 


\section{Introduction}

Gender inequality is a global issue. The term gender inequality delineates any prejudice or discrimination towards one gender or being biased towards it so much so that individuals treat disadvantageously with the same. A significant data reveals that women are the primary target of getting infested by gender bias and therefore, have fewer opportunities and negligible access to economic participation in many parts of the world. The status of women at workplaces happens to remain underrepresented even after the emergence of many women's rights and movements. However, the concept of gender inequality is a subject to meditate upon as many arguments by scholars, researchers, authors and writers regarding the same continue to remain unclear as no proper conclusion has been drawn. Exploring the vast literature on the same, de Beauvoir (1949) in her book The Second Sex delves deep into the differences between the two sexes- male and female and finds that the differences were taken for granted and that the reasons were unexplained for. For example, she wrote Saint Thomas categorised woman and declared her as "inessential being which from a masculine point of view is a way of positing the accidental character of sexuality" (Beauvoir, 1949, p. 43).

Further, taking arguments of many renowned scholars - Hegel, Aristotle and Hippocrates, Beauvoir (1949) attempted to make robust analysis of the so-called Second Sex. For instances Hegel's writings on sexuality consider one's sexuality to be a medium inherited from the genes. Similarly, Aristotle viewed the contribution of women in producing the foetus as null as he believes "woman just provided passive material, while the male principle is strength, activity, movement and life" (Beauvoir, 1949, p. 45). In the same context, the doctrines of Hippocrates also "recognised two types of seeds, a weak or female one, and a strong one, which was male" (Beauvoir, 1949, p. 45).

Taking these arguments of these scholars on board, Beauvoir (1949) studies in details the biological data of both male and female and concludes that woman in every aspect is weaker for example in height, weight, thickness of the skeleton, pelvis, muscular force, respiratory capability, haemoglobin count, overall shape and look, capability to menstruate, and give birth, nervous system, emotions, irregularity in endocrine functions and so on. Beauvoir further believes "these biological data are of extreme importance: they play an important role and are an essential element of a woman's system. Because the body is the instrument of our hold on the world" (p. 66). However, comparing the relative weight of the female and the male brain, it was concluded that the female is more advantageous than the male. Probing deeper into the same after much comparisons and calculations, biological, mathematical, functional and psycho-physiological it was concluded that males and females are no different and hence "equality is the result" ( $p$. 68). Although she provides strong reasoning towards the sensitivity of the female sex both by males and females, she strongly believes that the perceptions on the female sex are society inherited and not biologically inherited. She emphatically affirmed: "One is not born, but rather becomes, woman" (Beauvoir, 1949: 14).

In the light of these arguments and taking further arguments from various websites, books and views of researchers, this article aims to examine the gender barrier at the workplace. The following section outlines cases of gender inequality by reviewing literature from both Indian and western contexts.

\section{Gender Inequality at the Crossroad}

Different arguments and theories exist in the literature regarding gender inequalities. As a way of example, Alba asserts "gender equality is seeing males and females as being of equal status and value. It is judging a person based on their merit, and not viewing them as inferior or superior purely based on their gender" (Alba, 2018). Arguably, gender equality is not simply providing separate bathrooms for each sex rather equalising hiring decisions and payrolls 
only based on merit and not based on their sex. Another survey ${ }^{1}$ investigating the behavioural differences between men and women was conducted in 2017 by Turban, Freeman and Waber where the mails, communication styles, dominance in conversations and other essential behaviours were all closely probed for 500 employees in one office for four months, and the conclusion was astonishingly not assumed. It was found that although women and men shared an equal number of clients and customers, contributed an equal amount of time with their senior executives, were assigned equal time for the same job role and for spending time both for online and face-toface communication during work, along with the records of performance appraisement still men were promoted, and women were not. "The analysis suggests that the difference in promotion rates between men and women in this company was due not to their behaviour but to how they were treated" (Turban, Freeman and Waber, 2017). It was hence a clear demonstration that although the working patterns between women and men were accurately indistinguishable, at the end only men advanced.

Such trends do not affect males in working culture, and they remain numb towards the afflictions of women. Gregory describes "although males may remain insensitive to the adversities suffered by women employed in such a culture, and although they may at times remain largely unaware that practices and policies benefiting men at the same time negatively affect female workers, their conduct is no less pernicious" (Gregory, 2003, p. 16). Males view the roles and responsibilities of women are more related to family obligations and child-rearing capabilities hence, they may not be suitable for positions high in demand. Also in many contexts, women are considered to centralise their lives towards households as family and households are the mainstays of solidity and strength. However, Walby views and argues for an equitable division of

\footnotetext{
${ }^{1}$ The survey was conducted in a multinational business firm whose name and country is not revealed.
}

household duties and responsibilities that suffices the strategy of what she terms as "a consensual unit" (Walby, 1990, p. 64) to cope with gender inequality. She further supports the approach as she writes "if the fundamental unit locks men and women in one consensual unit, then there is no conceptual space to theorise the inequality between men and women" (p. 65). Hence, the pre-conceived notions that only women are accountable for household and family are based on false perceptions that although prevail around every work culture refutes the basis of gender equality.

Seemingly, Maharotra supports the fact as she expresses the perspectives of gender inequality in the Indian context. She views that "most women work much harder than their male counterparts. However, the invisibilisation of women's labour fails to get them their due share. The housework and childcare are not considered work. They are the duties of the woman and the rights of man to be taken care of" (Meharotrā, 2013, p. 35). She further highlights on the legal equality which subdues any inequalities that subsist in society. Such positive action eradicates inequalities towards "the weaker section of the community on a footing of equality with stronger and more powerful and disadvantaged sections so that each member of the community, whatever is by birth, occupation or social position, may enjoy equal opportunity of using to the full, his natural endowments of physique, of character and of intelligence" (p. 38). Social recognition or forming an identity in the society is largely dependent on the solid and substantial theories of prevalence, concatenation and depth of gender equality within a culture. The concept of gender is understood as how society or culture affiliates and expects from the contents of the culture. In a nutshell, gender attributes are merely created, fabricated and assumed by the society or culture. In this context, Butler opines "if gender attributes and acts, the various ways in which a body shows or produces its cultural signification, are performative, then theories no pre-existing identity by which an act or attribute might be 
measured; there would be no true or false, real or distorted acts of gender, and the postulation of a true gender identity would be revealed as a regulatory fiction" (Butler, 1999, p. 180). Butler here wants to emphasise and elucidate that all bodies are distinguished according to their gender only, and this distinction exists since the beginning of human subsistence which means everybody is equally created. However, then based on cultural and societal significance and expectations, these theories begin to lose their identity. Gender becomes something that is differentiated or calculated based on what that gender does or acts or performs. Thus gender reality is a result of the constant societal actions or performances. Butler here does not propose that the gender exactly knows what actions or performances he or she is going to endorse instead the actions are predetermined within the regulatory structure.

Women around the world are still a minority primarily at workplaces. Zastrow is of the view that "women are considered a minority group because for generations they have been subjected to discrimination and have been denied equal opportunities" (Zastrow, 2009, p. 423). The fact that men exceed women in being elevated to higher positions worldwide and in various sectors is something which is not only surprising but also has been largely accepted and stereotyped. Researches furnish tremendous knowledge for the fact that women often come across invisible barriers if not under one roof then outside and more surprisingly they still choose to remain silent. Bhattacharyya in her work "\#Metoo Movement: An Awareness Campaign" takes different examples from countries around the world and endeavours to make a close analysis on the most radical and revolutionary campaign the \#Metoo movement. She highlights the much-debated movement \#Metoo that bore its origin from Hollywood and stirred the entire globe. She believes that the movement provides space and opportunity for women to speak their heart out against the culprits and remains optimistic regarding the movement as she writes "The institutions/organisations might ignore the complaint of a single woman, but they are less likely to ignore collective voices" (Bhattacharyya, 2018, p. 9).

Groschl and Takagi in their book Diversity Quotas, Diverse Perspectives: The Case of Gender discuss on sexism and the causes of the glass ceiling which include "lack of career counselling and development for women, lack of management development opportunities for them, attitudes for male councillors and managers, the expected role of women in society, conflicts between personal and work life, and the organizational culture within which women work" (Groschl and Takagi, 2016, p. 155). This has been already mentioned by Camilla and Jeff (1998). ${ }^{2}$

In the Indian context too, much similar to other countries around the world shares a hypocrite agenda in pushing women towards success yet dragging them down along with their selfesteem mostly at workplaces. In this note Barua opines "it is almost baffling to understand how the majority of valuable, hardworking and high delivering women of India who constitute 50 per cent of the one billion Indian population and 80 per cent of the total world population have been relegated to the lowest levels of workspaces and sidelined in the decision-making strategies, defined narrowly by conservative hierarchies of linear leadership of male-dominated networks that allow little space for colours of diversity, individuality, and different strokes which are the hallmark of creativity, innovation, and competitive excellence" (Barua, 2017, p. 3).

However, experts suggest that women have the power to overcome all odds and come up with flying colours in all fields. Singh, in her book Organizational Behaviour: Text and Cases, quotes Anjali Bansal, the Managing partner at Spencer Stuart India. In the words of Bansal "for women to be successful at workplace, a tripartite effort is required-from the family and social environment, which encourages the

\footnotetext{
${ }^{2}$ This is a secondary reference. It could not be added in the reference list because I could not find the book.
} 
desire within the women to work from the work environment itself, which does not see marriage or maternity as reason for a woman to drop out or stagnate at the workplace, and finally, the drive, self-motivation and willpower of the women themselves" (Singh, 2015, p. 525). The hardships of women at workplaces thus are never-ending and primarily misinterpreted. Standing up in the maledominated realm and putting views needs undoubtedly lots of confidence and compassion.

The above literature review furnishes the situation women are at workplaces in the 21st century. This paper studies on the significant issues women have and obstacles they face mainly aiming to gender barrier that restricts them to grow at workplaces concerning the Indian context. The paper also furnishes with essential abilities and capabilities to leverage themselves from the current quandary.

\section{Women at the Workplace}

The Constitution of India grants equality towards both men and women. Not only this; but the Constitution also "empowers the States to adopt measures of positive discrimination in favour of women for neutralizing the cumulative socio-economic, education and political disadvantages faced by them" ( Meharotrā 2013, p. 40). However, the concept in the constitutional provisions has vacillated, and analysis drawn by many experts and researchers state that women have not been given equal opportunities to participate in any form of advantages as mentioned above. Sen, Bhattacharya and Sen also agree on the fact as they provide reports from Millennium Development Goals in 2014 that claim "in many countries, gender inequality persists, and women continue to face discrimination in access to education, work and economic assets and be active in government's participation (...) women tend to hold less secure jobs than men, with fewer social benefits" (Sen, Bhattacharya and Sen, 2016, p. 118). The basis of every society which assists in structuring a democracy is dependable on equality. The concept of equality describes the existence of legal rights.
Hence, equality regarding being uniform suggests that the presence of special privilege or opportunity is null and void. It also encompasses the notion of openness of opportunities to all irrespective of caste, creed or sex.

However, Indian society does not seem to observe or abate constitutional rights entirely. To emphasize a few out of 13 Constitutional Rights to Women like Article 15 (1) that suggests "the state shall not discriminate against any citizen of India on the ground of sex, Article 39 (d) that suggests the state to secure equal pay for equal work for both Indian men and women, Article 23 (1) that suggests traffic in human beings and forced labour are prohibited" (Devendar, 2017) studies reveal that there are uncountable cases where the constitutional rights for women are neither completely followed or subsided. On the same context, Balachandran closely analyses Kamala Das's My Story in his book Critical Essays on Commonwealth Literature where he writes "in India, women are placed on a pedestal and worshipped on the one hand and treated badly and enslaved on the other" (Seshadri and Balachandran, 2006, p. 136). Thus the status of women in India is complex and selfcontradictory. A long trailed history describes men to be the breadwinners and women to be homemakers. Indian women although are worshipped as a goddess but also are treated as mere objects for male satisfaction. Follesdal and Pogge affirm "women and their bodies are the symbolic-cultural sites upon which human societies inscript their moral order. Because women are typically seen as the symbols or bearers of culture, conflicts among cultural groups often are fought on the terrain of women's bodies, sometimes literally in the form of systematic rape" (Follesdal and Pogge, 2005 , p. 46). Since ages, women had been targets for rape, discrimination, abuse, polygamy, holocaust and other social evils. Such social structures have given precession to men over women that originated from family ideologies, rules, regulations, customs, culture, traditions brewing since ages altogether. Hence, women had been stereotyped as a 
creation that is subjected to stay indoors, bear children and look into family households and wellbeing of other members of the family. Packer condemns the "socially constructed nuances of everyday existence influence every aspect of an Indian women's life, including career choice and implementation" (Packer, 2014, p. 2).

Even though the existence of such patriarchal status in Indian society is still at large women have managed to step into workplaces and have successfully undertaken in varying career domains formerly male-dominated. "Since the eighties and nineties, there are more women in the workplace in India than there have ever been. There are more job opportunities for women, and thus there is an increase in the economic participation of women in rural as well as urban India" (Mieroop and Schnurr, 2017, p. 147). Although women were successful in stepping out from their houses and accepting challenges at workforces, however, there still exist many social and cultural barriers that hinder their growth and development in professional life.

\section{Gender Discrimination in the Workplace}

Despite the critical progressions in the status of women at workplaces inclusive of both socioeconomic, the concept of gender remains significant hindrances towards the achievement of power and authority. The theory of gender discrimination arises when there is a difference between personal opinions, perceptions, views, thoughts and values between the two sexes. In the Indian context, the persistence of gender bias can be observed at different levels and diverse forms because of the stereotyped thoughts that specific work type are male related and others are female related. "With respect to traditional jobs versus nontraditional jobs, women are often relegated to low-paying, clerical and administrative jobs, while men are often placed on career tracks that promise upward mobility and career advancement" (Mayhew, 2017). This theory is otherwise termed as gender division. Another theory is gender discrimination which embodies unfair treatment towards women.
Gender discrimination is a broad area, and it includes a plan to enfeeble the status of women and encourages preferences towards men over women like better careers, payrolls, assignments, performance evaluation and other aspects. The third theory is gender inequality which is deeply rooted in societal notions and stemmed from the social policies in favour of men and against women in all dimensions, especially at the workplace.

Indian society had generalised and judged men and women based on their perceptions rather than their respective abilities and capabilities. "Decades ago, researchers identified the central adjectives that people used to characterize men and women (...) where according to gender stereotypes, women are thought to be communal, and men are thought to be agentic" (Colella and King, 2018, p. 74). This has also been mentioned earlier by Broverman, Vogel, Broverman, Clarkson and Rosencrantz in $1972{ }^{3}$ Studies reveal that such stereotypes still dwell actively and are prevalent in many Indian workplaces. Gender division, gender discrimination and gender inequality all sum up to gender stereotyping and form prejudices against women at the workplace. The gender barriers make the workplace atmosphere less productive, create a hostile environment and restrict women to achieve their best and stay independent. The section below discusses various types of gender barriers experienced by women at Indian workplaces.

\section{Types of Gender Barriers}

This section discusses the many ways where gender barriers prevent women to successfully encounter in their endeavours to progress and achieve status and positions of command and control.

\section{Unequal Pay}

The Government of India passed a law - Equal Remuneration Act, 1976 which calls for Equal pay for Equal Work which implies "Duty of the employer to pay equal remuneration to men

\footnotetext{
${ }^{3}$ This is a secondary reference. It could not be added in the reference list because I could not find the book.
} 
and women workers for same work or work of a similar nature" (Ministry of Labour and Employment, n.d). This suggests no employer would pay his/her employee as remuneration in the form of cash or kind being more favourable towards the worker thus out casting another worker of opposite sex for doing or performing the same job roles and carrying the same job responsibilities. However, the real scenario in India regarding equal pay towards employees and not via discrimination is a dream yet to be achieved by Indian women. Many surveys in the recent past were conducted to investigate on the unequal pay in workplaces where the findings were though shocking yet expected.

The International Labour Organisation executed one such survey in the year 2017 which revealed "the extreme levels of disparity in wages for women in India. The survey quite clearly reflected that men earn more than their women counterparts for similar jobs. The gap in many cases is as staggering as 30 percent" (IANS, 2018).

Before the ILO survey in 2017, another survey by Monster Salary Index was conducted in the year 2016. Data collected showed that "men earned a median gross hourly salary of Rs 231, compared to women, who earned only Rs 184.8" (PTI, 2018). That suggests women who are working under equal job roles as that of men receive 20 per cent less salary. This denotes the discriminatory status of salary determination in India. The report further suggested that the concept of unequal pay is also experience dependent. For instance, it stated " while men with 0-2 years of experience, earned about $8 \%$ higher median wages than women, men with 6-10 years of experience, earned 15\% more" (PTI, 2018). This means, although experience at work is an essential factor in pay-rise, it still has a limitation to gender. Men with experience receive a higher salary-rise than women with same experience.

Women may be physically weak, but they have immense power to fight for a cause when supported by the law. Many women are not aware of the power they bear to bring social change and those who believe they cannot do much. The self-discouraging nature often makes women weaker, and they strongly oppose to fight even for themselves. Hence, women who face such unequal pay at workplaces must voluntarily approach the law. On the subject, Flavia Agnes, lawyer and activist, points out "although the laws for protecting equal wage rights are not sufficient in India, the existing ones have to be put to use. If people do not come with cases of wage discrimination, reports of the widening wage gap will continue to surface" (IANS, 2018).

\section{During Interviews}

During the selection process of to-be employees mostly women, the employers and the interviewers leap to questions more or less related to their personal lives. Questions like "Are you planning to start a family soon? Are you pregnant right now? Are you trying to get pregnant? How many children do you want (Biddlecombe, 2018)? And many other questions which arise from the stereotypical mindsets of the employers and interviewers holding a conception that women may become a liability or a burden or a risk to their organisation if they are pregnant or already mothers or planning for a second child or anything of that sort.

A bright example supporting this fact is of Jeena Sharma who "discovered this preconceived sexist notion could lead an employer to view hiring a woman as a risk" (Biddlecombe, 2018). Shockingly, such questions came from a woman interviewer. Studies reveal that female employers or interviewers equally reveal intrinsic discrimination against women candidates and in many harsh ways.

In India, interviewers do much think about the consequences that women candidates face after being queried about marriage or children. A leading website published an interview with Aisha (name changed in the site for valid reasons) talks about a company in Mumbai that has strict guidelines "not to hire women if they are pregnant, soon to be married, or planning 
to have children soon" (Johari, 2017). Another disturbing case comes from women candidates who applied at banks in Chennai who "reported wanted to know whether women candidates were pregnant and when they had their last period, and clearly stated that pregnancy would be a bar for immediate appointment" (Johari, 2017). Expectedly, male candidates have better opportunities to grab jobs as they would never have the capability to bear and rear a child and hence no certainleaves. It is, however, a sad story that women are bearing similar work abilities to men and with similar job responsibilities to deliver, face a setback even before entering into the workplace for their biological ability to conceive and start a family.

\section{Career Advancement}

Much of the issues related to women and workplaces and their career advancements have gained enormous attention over the recent years. Srivastava is of the same view as he writes "issues related to women have been given due weightage in recent years" (Srivastava, 2005, p. 7). While women have successfully stepped into the corporate world and perform excellently, conquering the top executive positions is still a distant dream. "In India, women comprise only one-fifth of the total labour force, and the gap between men and women widens as the leadership ladder goes up, with only 7 percent of the board room seats are held by women" (Peoplematters, 2015). This concept of barrier is termed as 'glass ceiling,' which according to Chodorow "began to appear in the mid-1980s (...) is an appealing metaphor, carrying with it the sense that what is immediately above- an upper floor, the sky, even- may look reachable but, when a woman tries to reach it, a previously invisible glass barrier turns out to be in the way" (Chodorow, 2012, p. 94) The term glass ceiling' is commonly found in literature and referred to by women activists, researchers and other eminent bodies who work for the betterment and elevation of women in every domain as a barrier although not a visible one that obstructs women to reach the topmost positions, and attain power and authority at workplaces. One can blame the stereotypical thoughts of men who firmly believe that if women empower and reach the top, they will be equal to them. Men as creations and inherent characteristics do not like to be instructed. Hence, acquiring a level lower than women and following orders and instructions messes them up.

Obstruction in career advancements of women or the glass ceiling phenomenon is carried out in many ways. Many women in India remain untrained. While a significant part of Indian companies will to provide management training and mentoring, women in many cases are found not to cooperate because of lack of awareness of their potentialities and calibre and confidence in self. Still, a large part of women who do believe in themselves and are hardworking are not appreciated for their work and not involved during decision makings. Although a vast literature and arguments on who is a better decision maker has not yet achieved any sturdy answer, the stereotypical men mindset understands that women always deal with situations emotionally and hence, are bad decision makers, also of "being less intelligent, less able to meet the demands of the job, less competent and in general have to work much harder than men to get the same results" (Nath, 2000, pp. 44-52). In the same context, Billing and Alvesson believe that leadership styles and gender are not interdependent and that both women and men demonstrate same leadership styles as they write "[q]uitea number of studies have dealt with differences between women and men as to their leadership styles. These have shown that style and behaviour are not directly linked to gender and that women and men are very similar in their approach to leadership" (Billing and Alvesson, 1994, p. 78). Huston (2017) in this view understands that people have underestimated women and led a way to believe that men are better decision makers. People often fail to recognise that decisions made by women are more analysed than that by men. Huston writes "it may be hard to believe that decision-making has a gender component, that someone would give a man an understanding nod but give a woman a raised 
eyebrow for making the same call" (Huston, 2017, p. 3).

The Indian context also constitutes barriers that although seem impartial or unbiased, still illustrate male dominance. This illustration of male dominance is at times unavoidable, and nothing much can be done about it. Hence, it remains unresolved because it is deeply enrooted in the Indian culture. For example, women are expected to carry family responsibilities, are assumed to move along with husbands overseas with assignments and rotations, are not included in any informal communication say at bars/coffee shops after working hours or at a sports club in the weekends that might lead to a discussion of grey matters and so on.

Although The Company Act, 2013, issued by the Securities and Exchange Board of India (SEBI) had made strict guidelines "to have at least one woman on their boards - either as an executive or a non-executive director before April 1, 2015 (...) The number of women in Indian boardrooms is lower than the average of developing countries" (Chatterjee, 2017). India still is way behind in representing women in boardrooms, ranking 26th worldwide which is lower than the average developing countries, the same site suggests. Hence, it is required that both women and organisations must cooperate and collaborate with norms and regulations to together move forward to crack the glass ceiling.

\section{Sexual Harassment}

One of the most common forms of gender barrier at the Indian workplace is sexual harassment. As a serious issue, sexual harassment has been receiving much negative attention in India since 1997 when the case of Vishakha vs. The State of Rajasthan was at large. The literature on the same describes Bhanwari Devi as a woman social worker who was ganged raped brutally for stopping child marriage. She filed a petition in the Supreme Court. The court soon set guidelines commonly known as Vishakha guidelines, and in 2013 The Sexual Harassment of Women at Workplace (Prevention, Prohibition and Redressal) Act was passed by the Indian parliament. Although Bhanwari Devi did not receive any justice, yet the case almost altered the Indian law and its approach towards Sexual Harassment across many organisations in multifarious sectors. "Despite these advances, a 2015 study by the Federation of Indian Chambers of Commerce and Industry and EY suggested that 36 percent of Indian companies and 25 percent of multinational corporations in India were, not compliant with this Act" (D'Costa, 2017).

According to the Act "Sexual harassment includes unwelcome sexually determined behaviour such as physical contact, demand or request for sexual favours, sexually coloured remarks, showing pornography and any other unwelcome physical, the verbal or nonverbal conduct of a sexual nature" (IndiaFillings, 2018).

While at one edge, there are laws to protect women's rights and dignity, there are still a large number of Indian women employees who do not communicate about the problem of sexual harassment. The Indian National Bar Association conducted one survey in 2016 where questions were put to approximately 6047 participants from most of the cities of India and varying work sectors including both men and women. It was found that 38 per cent of the candidates have faced sexual harassment at workplaces. The first post declares "[m]ost of the women victims dealt with it on their own instead of lodging a formal complaint with the management. Fear, embarrassment, lack of faith in the redressal mechanism and unawareness were some of the reasons cited for not reporting the management" (FPStaff, 2017).

Although a number of countries are recorded identifying and researching on sexual harassments primarily at workplaces, there is no powerful or rigid conclusion as yet that can be drawn regarding the history or origin and the aftermaths of sexual harassments both in individual and organisational levels. Sexual harassment at workplaces as the worst form of barrier not only impacts job but has severe consequences on health and mental condition 
of the women. Studies reveal that a sexually harassed woman has a fair chance of losing her job or the risk of not getting a promotion if she does not adhere to the unwanted sexual desires of any higher representative at the workplace. In many other circumstances, such unwelcome sexual act of other workers may develop unfriendly and offensive environment further pressurising her to quit her job. Further, if she stays back, she may not be able to perform well owing to psychological issues after sexual harassment. A report by $\mathrm{FICCl}$ found that "even innocuous remarks such as crude comments, innuendos or inappropriate jokes over time can cause significant psychological distress" (FICCl, 2015, p. 11). In this context, Bhattacharya writes "when the most empowered women of Hollywood, Westminster and elsewhere have taken years/decades to speak out against incidents sexual harassment, one can easily imagine why ordinary/common women fear to speak against the perpetrators" (Bhattacharya, 2018, p.8). However, following the worldwide indignation, the \#Metoo movement continues to gain prominence and recognition in India especially when a former Miss Universe from India alleged a veteran superstar of Bollywood to have sexually harassed her ten years ago on the film sets. Along with him, there was a choreographer who supported the veteran star to continue exploiting her. Within no seconds star celebrities came up to support what the former Miss Universe had to say.

Interestingly, no sooner than the case rode a new wave in India, a series of old cases started to reopen engulfing eminent personalities like politicians, book writers, music composers, producers, directors, artists, singers, advertising managers, comedians and many more. While many of them begged apologies there were still many who declared themselves not guilty and threatened the complainants with charge sheets and legal proceedings. The indictments in India exploded on social media just like a wild-fire and provided a vent for the victims to speak out about their experiences and abusers. The movement has since then resulted in sacking or resignation from their jobs, denunciation, criticism and separation from the staff and members of their relevant industries and resentment from their fans and public. The \#Metoo movement has built a stepping stone for the victims to name their abusers openly so much so that a \#Metoo tracker has been initiated by "the Indian Express to provide details of the status of each case that the Indian Express has reported on" (Indian Express 2018). This tracker would keep in the record the significance of each case on a daily basis. Surely, the \#Metoo Movement has opened up the dark secrets of famous personalities and has concrete ways and opportunities for the victims to speak against their abusers by providing them with the courage to do so. This has in many ways given serious blows to the ones who are accused of their actions and also provided lessons to those around. "As the \#Metoo movement continues to tear down millennia of patriarchy and male entitlement as well as the institutionalised silence of sexual abuse victims, individuals and organisations around the globe are finding incredible ways to speak up" (David, 2018).

\section{Breaking the Gender Barrier}

Around the world, there has been awareness regarding gender barriers and women's progression towards breaking the gender barrier code. The present scenario at workplaces demands competent skills that Indian women are capable of but not exhibiting and abilities that they are inheritedwith. Changes begin by changing self-first. The points below discuss few capabilities that women need to discover first and abilities women need to implement to bring changes to themselves and thus, elevate their identity at workplaces.

Self-Awareness: Most of the women employees in Indian workplaces are reluctant to come out from their shell. Confined within the boundaries of family pressure and lack of support from organisations they work for, women have long forgotten the inner talent they carry. Hence, they need first to take some time from their daily schedule and attempt to develop skills of self-introspection. Women need to identify their strengths and 
weaknesses and look for opportunities by discarding fear. Further, they need to work harder to strengthen their strengths, weaken their weakness, make opportunities their aims and kick off fear.

Communication: Women at workplaces are mostly expected to be humble, nice and pleasant speaking. However, women can always choose any of the communication styles like passive, aggressive, manipulative and assertive as and when required but with clarity and conciseness. Applying different communication techniques to different events and in different contexts would wipe out the stereotypical mentality of men towards the woman that they can always be controlled and tamed.

Courage: Another cultivation women need to incorporate within themselves is courage. Many people believe that women have neither voice to speak nor courage to rise. However, women need to empower themselves by standing up for their own dignity. Who else will? Inculcating courage will enhance confidence level and boost up as a warning to male counterparts not mess with them. Be it situations like sexual harassment, promotion, unequal pay or any other form of injustice; women need to speak up and raise voice against the situation with courage.

Studies reveal that women are no less when it comes to talent, have better tolerance power, better communication style, management abilities, conflict resolution ability and many other skills that need nurturing and polishing especially at workplaces only that they are not encouraged. Rankin and Caccamise precisely justify "the skills that tend to be associated more with women such as collaboration, better communication, and focus on the whole than with men are the most important skills in ensuring teams function effectively" (Rankin and Caccamise, 2017, p. 9). This has already been mentioned by Wolley, Maone and Berinato in 2011. ${ }^{4}$ At the same time, a leading

\footnotetext{
${ }^{4}$ This was originally mentioned by Wolley, Maone and Berinato in 2011. As I could not find the name of the book it could not been added in the reference section.
}

website mentions "Today, women still get offered fewer of the high visibility, missioncritical roles, and international experiences that are important to reaching the highest levels of leadership" (RPappas, 20172017). This proves although women are capable of delivering highquality tasks yet they are not given ample space and opportunities to prove themselves. Hence, it is the responsibility of organisations to guide and help prosper women and their talent. Also, organisations must ensure that their policies, practices and decision making processes identify and prevent gender discriminations. Organisations must also provide management training and encourage women employees to participate in teambased organisational settings which promote better opportunities and space for employees to collaborate and perform tasks.

\section{Conclusion}

This paper studied gender division, gender inequality and gender discrimination at Indian workplaces. The paper discussed the predicament of women at workplaces about the Indian context. Types of gender discrimination were discussed along with the competencies and skills to be developed by women in their lifestyles. Women will have to alleviate feelings of agony, frustration, anger and discouragement and detail the far-reaching layers of their perceptions, values, ethics and leadership skills and abilities that would provide them with new measurements and challenges to the opposite sex at workplaces. The fact that women are capable of bringing many transformations with their abilities is what they must realise first. Organisations play a pivotal role in leveraging the position of talented women. Hence, they must cooperate with women employees to build their confidence level and help them reach success. It may be thereby concluded that the dual combination of women's strengths and development and the involvement of organisations would eradicate gender barriers from workplaces and society in the near future. 


\section{References}

Alba, B. (2018, September 19). To achieve gender equality, we must first tackle our unconscious biases. Retrieved October 26, 2018, from

https://theconversation.com/to-achievegender-equality-we-must-first-tackle-ourunconscious-biases- 92848

Barua, P. (2017). Leadership by Proxy: The Story of Women in Corporate India. S.L.: Bloomsbury India.

Beauvoir, S. D. (1949). The Second Sex.NewYork: Vintage Classic.

Bhattacharyya, R. (2018). \# Metoo Movement: An Awareness Campaign. International Journal of Innovation, Creativity and Change, 3(4), 8-8. Retrieved October 4, 2018, from http://www.ijicc.net/images/Mrach18_spe c_edition/battacharyarra_March18.pdf

Biddlecombe, S. (2018, February 27). Discriminating against women in job interviews is illegal - so why is it still happening? Retrieved October 4, 2018, from https://www.stylist.co.uk/longreads/job-interview-questions-pregnantwomen-maternity-leave-discriminationsexism/192028

Billing, Y. D., \& Alvesson, M. (1994). Gender, managers and organizations. Enskede: TPB.

Butler, J. (1999). Gender trouble: Feminism and the subversion of identity. New York: Routledge.

Chatterjee, J. (2017, March 07). Glass ceiling: Gender diversity in Indian boardrooms still a distant reality. Retrieved October 4 2018, from https://www.financialexpress.com/opinion /glass-ceiling-gender-diversity-in-indianboardrooms-still-a-distant-reality/578761/

Chodorow, N. (2012). Individualizing gender and sexuality: Theory and practice. New York: Routledge.
Colella, A. J., \& King, E. B. (2018). The Oxford handbook of workplace discrimination. Cary: Oxford University Press.

D. (2017, August 24). Constitutional and Legal Rights of Women in India. Retrieved October 26, 2018, from https://www.2thepoint.in/constitutionallegal-rights-women-india/

D' Costa C. (2017, August 14). Preventing workplace sexual harassment. Retrieved October 4, 2018, from https://www.livemint.com/Opinion/KA80T P83PZx7yFNEJAfx3L/Preventing-workplacesexual-harassment.html

David, S. (2018, October 16). This Stunning Google Intercative Map Shows \#Metoo Has Reached Every orner of India. Retrieved October 16, 2018, from https://www.news18.com/news/buzz/thisstunning-google-interactive-map-showsmetoo-has-reached-every-corner-of-india1910179.html

FICCl. Fostering Safe Workplaces (p. 13, Rep.). (2015). Kolkata: Ernst \& Young LLP.

FPStaff. Sexual harassment at workplace: $69 \%$ victims did not complain to management, says survey. (2017, January 05). Retrieved October 4, 2018, from https://www.firstpost.com/india/sexualharassment-at-workplace-69-victims-didnot-complain-to-management-says-survey3189524.html

Føllesdal, A., \&Pogge, T. W. (2005). Real world justice: Grounds, principles, human rights, and social institutions. Dordrecht: Springer.

Gregory, R. F. (2003). Women and Workplace Discrimination: Overcoming Barriers to Gender Equality. New Brunswick, NJ: Rutgers University Press.

Gröschl, S., \& Takagi, J. (2016). Diversity quotas, diverse perspectives: The case of gender. London: Routledge.

Huston, T. (2017). How women decide: Whats true, whats not, and what strategies spark the best choices. Place of publication not identified: Mariner Books. 
IANS. (2018, March 08). Equal pay for equal work still a distant dream for Indian women (March 8 is International Women's Day). Retrieved October 4, 2018, from https://www.businessstandard.com/article/news-ians/equalpay-for-equal-work-still-a-distant-dreamfor-indian-women-march-8-isinternational-women-s-day118030800572_1.html

Indiafilings. (2018, January 17). Sexual Harassment at Workplace - Rules \& Regulations - IndiaFilings. Retrieved October 04, 2018, from https://www.indiafilings.com/learn/sexualharassment-workplace/

Indian Express. (2018, October 16). The \#MeToo tracker by the Indian Express. Retrieved October 16, 2018, from https://indianexpress.com/article/india/m e-too-tracker-the-indian-express-5404631/

Johari, A. (2017, January 03). Marriage, pregnancy, children? The unfair questions asked of women job seekers in India. Retrieved October 4, 2018, from https://scroll.in/article/669969/marriagepregnancy-children-the-unfair-questionsasked-of-women-job-seekers-in-india

Mayhew, R. (2017). Implications of Gender Bias in the Workplace. Retrieved October 4, 2018, from http://smallbusiness.chron.com/implicatio ns-gender-bias-workplace-2865.html

Meharotrā, M. (2013). Gender Inequality in India. New Delhi: Prabhat Books.

Mieroop, D. V., \& Schnurr, S. (2017). Identity struggles: Evidence from workplaces around the world. Amsterdam: John Benjamins Publishing Company.

Ministry of Labour and Employment.(n.d.). Retrieved October 04, 2018, from https://labour.gov.in/womenlabour/equalremuneration-acts-and-rules-1976

Nath, D. (2000). Gently shattering the glass ceiling: Experiences of Indian women managers. Women in Management
Review, 15(1), 44-52.

doi:10.1108/09649420010310191

Packer, S. S. (2014). India's Working Women and Career Discourses: Society, Socialization, and Agency. Lanham: Lexington Books.

People Matters Media Pvt. Ltd. (2015, December 21). 6 barriers for women's career advancement. Retrieved October 4, 2018, from https://www.peoplematters.in/article/dive rsity/6-barriers-womens-careeradvancement-12645

PTI. (2018, March 07). Retrieved October 4, 2018, from https://economictimes.indiatimes.com/ma gazines/ panache/gender-pay-gapscenario-daunting-in-india-women-getpaid-20-less-thanmen/articleshow/63204351.cms

Rankin, P. and Caccamise, D. Why Women Aren't Where They Are Needed in the Workforce: Putting the Pieces Together. The Sasakawa Peace Foundation Expert Reviews Series on Advancing Women's Empowerment, 2017

Sen, S., Bhattacharya, A., \& Sen, R. (2016). International Perspectives on Socio-Economic Development in the Era of Globalization. Hershey, PA, USA: Business Science Reference.

Seshadri, C. V., \& Balachandran, K. (2006). Critical essays on Commonwealth literature: A festchrift to Prof. C.V. Seshadri. New Delhi: Sarup\& Sons.

Singh, K. (2015). Organizational Behaviour: Text and Cases, 3rd Edition. New Delhi: Vikas Publishing House.

Srivastava, S. K. (2005). Applied and community psychology: Trends and directions: Proceedings of the international conference, 26-28 February, 2005. New Delhi: Sarup\& Sons.

RPappas (2017, January 19). 10 Big Issues Women Face at Work and What Leaders Can Do to Help. Retrieved October 27, 
2018, from

https://www.catalyst.org/blog/catalyzing/ 10-big-issues-women-face-work-and-whatleaders-can-do-help

Turban, S., Freeman, L., \& Waber, B. (2017, October 27). Gender inequality in the workplace is down to bias, study finds. Retrieved October 04, 2018, from https://www.irishtimes.com/business/wor k/gender-inequality-in-the-workplace-isdown-to-bias-study-finds- 1.3268490

Walby, S. (1990). Theorizing Patriarchy. London: Basil Blackwell.

Zastrow, C. (2009). Introduction to social work and social welfare: Empowering people. Boston, MA: Cengage Learning. 